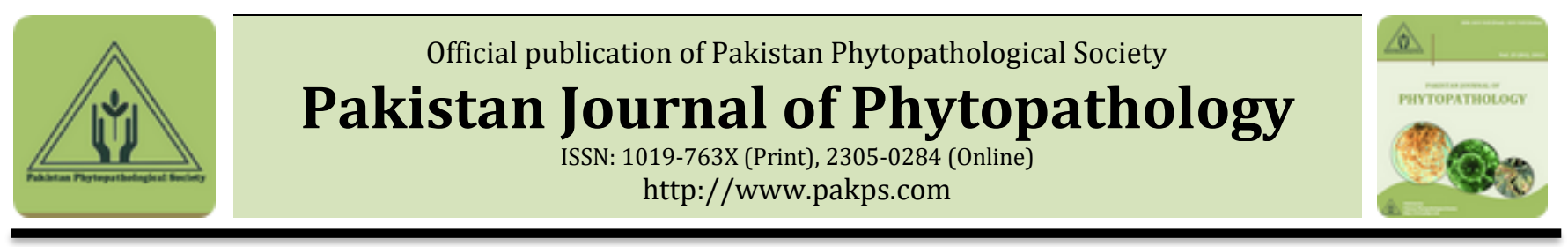

\title{
EVALUATION OF RAPESEED-MUSTARD GERMPLASM AGAINST ALTERNARIA LEAF BLIGHT UNDER LOCAL FIELD CONDITIONS
}

\author{
aMuhammad Z. Latif*, amran U. Haq, bSabir H. Khan, aAmer Habib, cSajjad Khuwaja, aArslan Shehroz, \\ aNoman Nazir, dImran Ramzan \\ a Department of Plant Pathology, University of Agriculture, Faisalabad, Pakistan. \\ ${ }^{b}$ Ayyub Agricultural Research Institute, Faisalabad, Pakistan. \\ ${ }^{c}$ Regional Agriculture Research Institute, Bahawalpur, Pakistan. \\ ${ }^{d}$ Department of Agronomy, University of Agriculture, Faisalabad, Pakistan.
}

\begin{abstract}
A B S T R A C T
Rapeseed-mustard is the second most important oilseed crop after soybean. The two species of Brassicaceae family Brasica napus L. and B. rapa L gain the great importance from world's commerce as the seed of both species contain about $40 \%$ oil content with $35-40 \%$ meal protein. There are many pathogens involve in the reduction of crop yield, Alternaria leaf blight is one of them. Among genus Alternaria, A. brassicae, A. brassicola, and A. raphai are important species from economic concerns throughout the world. The screening of rapeseed-mustard varieties/lines was carried at Regional Agriculture Research Institute (RARI), Bahawalpur. Total 28 varieties/lines were screened out against Alternaria leaf blight under field conditions. Normal agronomic practices were followed during the experiment. The pathogen was isolated from diseased plants and purified by using Single Spore Technique under aseptic conditions. It was noticed from the experiment that 8 varieties/lines showed moderately susceptible response while 16 were susceptible and 4 were highly susceptible. Among these 28 no varieties/lines showed highly resistant or resistant response. This study can be helpful for researchers to enhance the production potential of rapeseedmustard in future.
\end{abstract}

Keywords: Alternaria blight, A. brassicae, Aseptic, meal protein, single spore technique

\section{INTRODUCTION}

Rapeseed is often called mustard is the second most important oil crop after soybean. The annual production of rapeseed is 70.05 million metric tons during 2015-16 (Cimini, 2016). China stands first in production of rapeseed with annual production of 14,931 million metric tons (Kumar, 1999). Pakistan imports oilseeds of 2.63 Million Metric Tons during the year 2015-16 (FAS, 2018) which is a major burden on country economy. Rapeseed mustard is cultivated almost throughout the world. The Alternaria blight in Brassicaceae family was first time reported by Berkeley in 1836. Alternaria

Submitted: May 24, 2018

Revised: July 24, 2018

Accepted for Publication: December 17, 2018

* Corresponding Author:

Email: zunair.latif@uaf.edu.pk

(C) 2017 Pak. J. Phytopathol. All rights reserved. blight of brassica has been reported from all over the world including Pakistan and yield losses are up to 27\% (Kolte, 1985; Yadav et al., 2014). Study showed yield losses from disease $46-47 \%$ and $35-38 \%$ in yellow sarson and mustard in India (Kolte and Awasthi, 1987) and 20-30\% in Canada (McDonald, 1959). Khan et al., 1998 reported that 26.5\% and $22.6 \%$ infections due to $A$. brassicola and $A$. brassicae respectively and $50.9 \%$ as combine effect of both pathogens. In Nepal, the disease appeared in epidemic form during 1992-93 and 32 to 57\% yield losses were observed. Akhtar et al., 2014 reported the fungus Alternaria as leaf spot pathogen of edible canola from Pakistan. Environmental factors such as Temperature, frequent rains and high relative humidity play a magnificent role in disease initiation and spread (Shrestha et al., 2010). Among the genus Alternaria three species $A$. brassicae, $A$. brassicola and $A$. raphai are most frequently isolated from Brassicaceae family (Varma and Saharan, 1994). However, A. brassicae, A. brassicola are most 
destructive as compared to A. raphai which is mostly common in Canada. The genus Alternaria is also involved in the destruction of various vegetables of economic importance (Mamgain et al., 2013). The yield is adversely affected by the disease, and the pathogen not only cause reduction in net yield but it also affects the quality of produce (Prasad and Lallu 2006; Mamgain et al., 2013). The pathogen infect plant at all growth stages. The pathogen survives through spore (conidia) or mycelium in diseased plant debris, weed host and seeds (Humpherson-jones, 1989). As the pathogen is polycyclic, air borne spores and infected seeds act as primary source of inoculum for the next infection cycle (Kolte, 1985). The infection initiates after landing of conidia on leaf surface of the host plant. Presence of moisture favors the germination of the conidium and because of hyphal growth on host plant surface, necrotic lesions become visible as the fungus is necrotroph (Cho et al., 2009; Agrios, 2005). Symptoms appear on leaves, stem and siliquae as black spots and the typical symptom of the disease is the formation of concentric rings of brown color. $A$. brassicae produced grey spots, $A$. brassicola produced black sooty velvety spots and spots produced by $A$. raphai showed yellow hollow around them which may vary as per host and environmental conditions (Saharan and Mehta. 2002; Meena et al., 2010). Various chemicals and systemic fungicides have been evaluated against the disease as a part of management strategies (Mridula et al., 1994). There is no variety/line/genotype highly resistant against this chronic disease (Gupta et al., 2017). So, keeping in view the economic value of the crop and disease present study was planned for the selection of resistant germplasm which could be useful in future breeding programs. As resistant source is an integral part of integrated disease management (IDM) strategic plan and can only be guaranteed for a sustainable production.

\section{MATERIALS AND METHODS}

The research was conducted at research Area of Regional Agriculture Research Institute Bahawalpur during 2015-16 Table 1. Disease Rating Scale developed by Meah, 1994.

\begin{tabular}{cccl}
\hline $\begin{array}{c}\text { Rating } \\
\text { Scale }\end{array}$ & Reaction & Disease severity $\%$ & \multicolumn{1}{c}{ Description } \\
\hline 0 & HR & 0 & No visual symptoms on leaf surface \\
\hline 1 & R & $0.1-6$ & Small sized dots covering 0.1 to 6 \% or less leaf surface \\
\hline 2 & MR & $6.1-12$ & Gray circular spots having concentric rings covering 6.1 to 12\% leaf surface \\
\hline 3 & MS & $12.1-25$ & $\begin{array}{l}\text { Enlarged lesions. Gray circular spots having concentric rings covering 12.1 } \\
\text { to 25\% leaf surface }\end{array}$ \\
\hline 4 & S & $25.1-50$ & Enlarged lesions collapsed covering 25.1 to 50\% leaf surface \\
\hline 5 & HS & $50.1 \&$ above & $\begin{array}{l}\text { Collapsed lesions with black boarder around concentric rings covering } \\
50.1 \% \text { or more leaf surface, defoliation occur }\end{array}$ \\
\hline
\end{tabular}

under local field conditions. The varieties/lines were sown in 2 rows of each 4-meter length per plot with row to row distance of $45 \mathrm{~cm}$ by following randomized complete block design with 3 replications. No agronomic practices were followed during the experiment. Data was recorded from randomly selected 5 plants of each variety/line. Disease severity percentage was recorded on the basis of infected area of leaves. On the basis of disease intensity varieties/lines were classified into different groups as highly resistant, resistant, moderately resistant, moderately susceptible, susceptible and highly susceptible (Table 1). For the isolation of the associated fungal pathogen, leaf samples with characteristic symptoms were collected from the Research Area of RARI, BWP (Figure 1) and brought to Plant Pathology section for further necessary proceedings. Leaf samples were washed in tap water, cut in to small pieces, dipped into $1 \%$ solution of $\mathrm{NAOH}$ for 30 seconds followed by three consecutive washings in distilled water, placed the sample on blotter paper and shift to Laminar Flow Chamber. These pieces were transferred onto Potato dextrose agar (PDA) containing petri plates under aseptic conditions to avoid contamination and incubated at $25^{\circ} \mathrm{C}$ for the development of mycelial growth. After 24 hours, fungal mycelia start growing from these infected leaf pieces (Figure 2). The inoculated plates were kept in incubator at $25^{\circ} \mathrm{C}$. The isolated fungus was further purified through Single Spore Technique (Choi et al., 1999). Data was recorded by modified 0-5 scale developed by Meah, 1994 .

$$
\text { Disease Severity }(\%)=\frac{\text { Infected area of leaf }}{\text { Total area of leaf }} \times 100
$$

After the appearance of cottony growth on media plate, the mycelial growth of pathogen was taken out with the help of sterilized needle, placed onto the surface of glass slide having a drop of methyl blue and was then covered with a clean cover slip. The slide was observed under compound microscope and the pathogen was identified (Figure 3). 


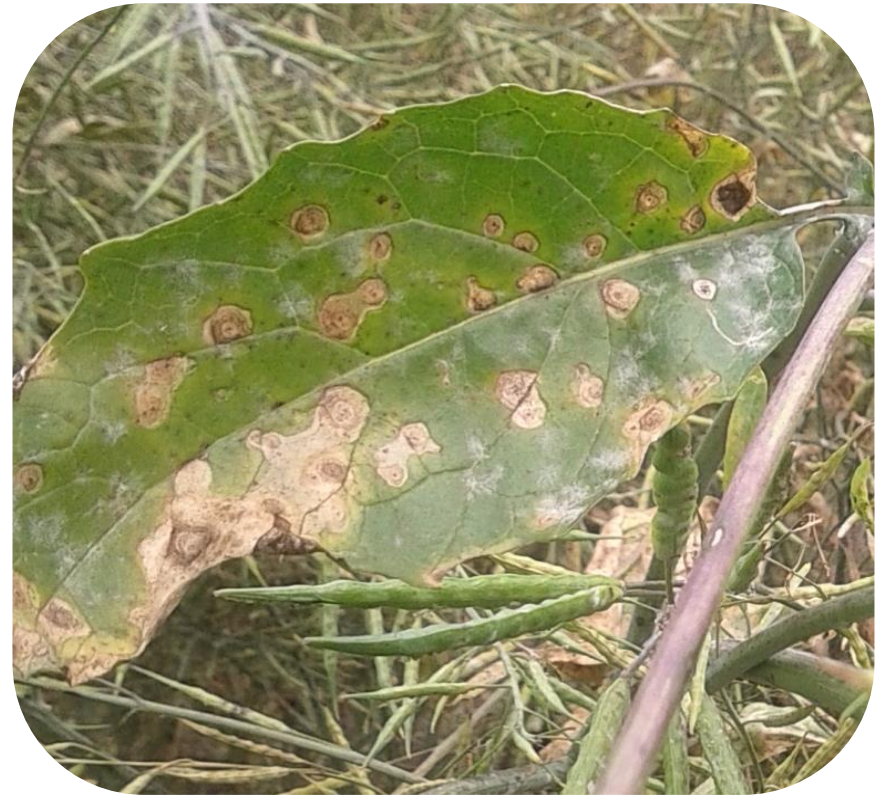

Figure 1. Leaf infected with Alternaria blight

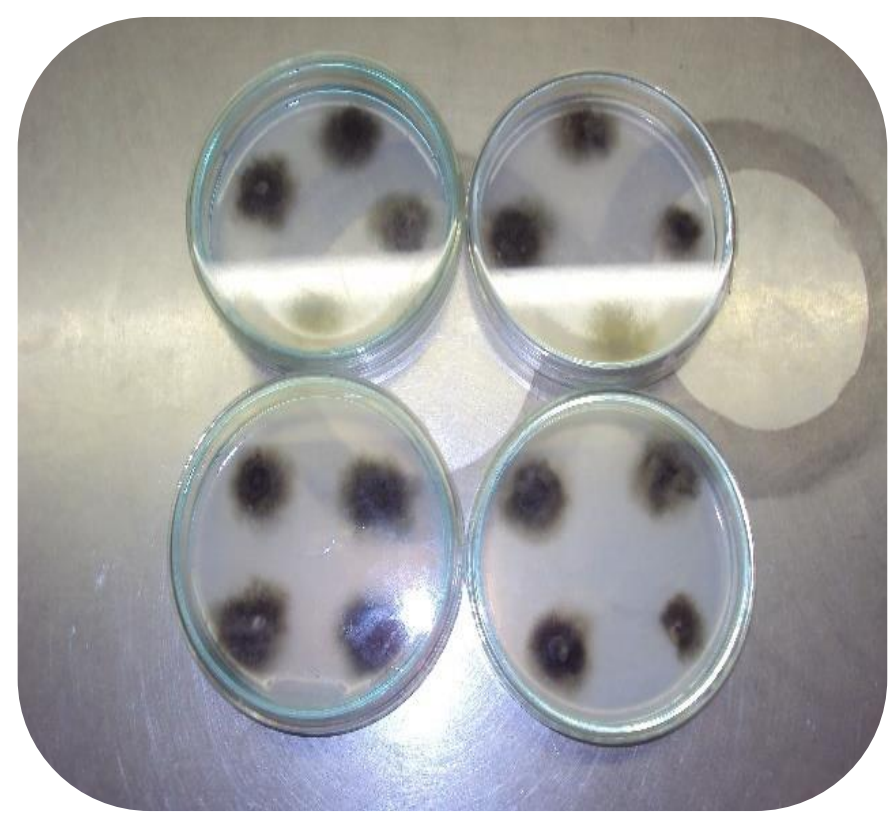

Figure 2. Fungal colonies on PDA originating from infected bits

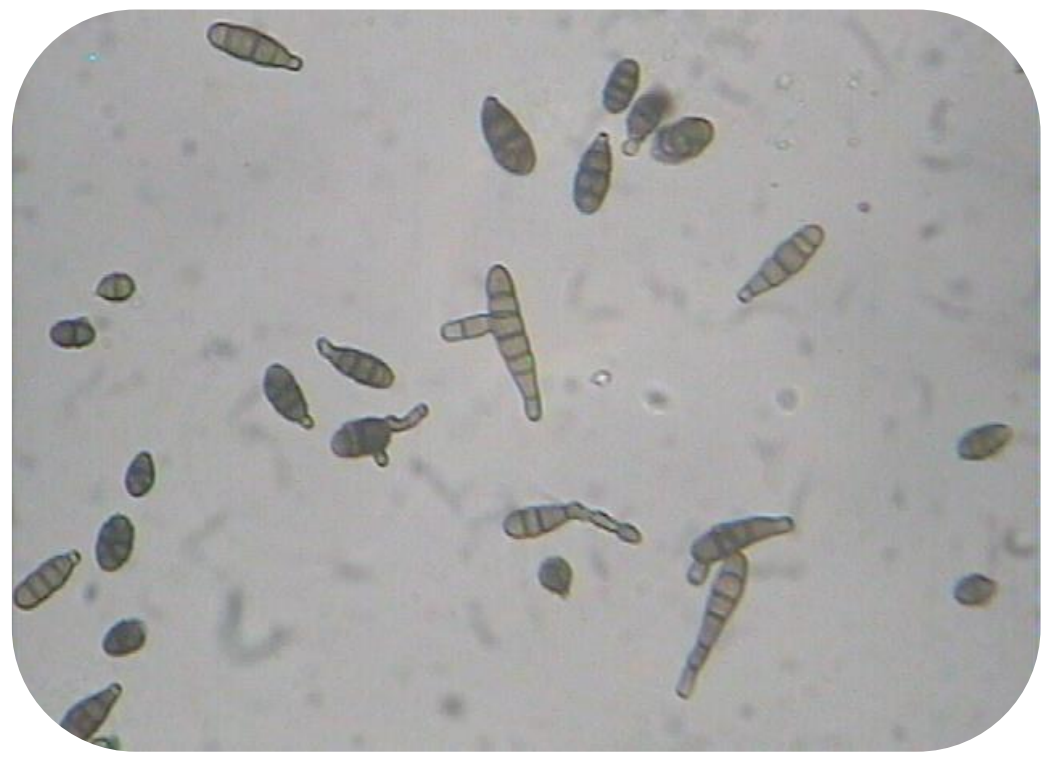

Figure 3. Spores of Pathogen

\section{RESULTS AND DISCUSSION}

Total 28 varieties/lines were screened out Regional Agriculture Research Institute (RARI), Bahawalpur under local field conditions. It is noticed from the result that among all varieties/lines none was found to be resistant, moderately resistant or highly resistant. Eight varieties/lines (BRJ-1004 (23.34\%), BRJ-1005 (15\%), BRJ-1455 (21.67\%), BRJ-1456 (15\%), BRJ-1457 (21.67\%), BRJ-1458 (20\%), BWP-RAYA (18.34\%), and KNP-RAYA (13.34\%) were identified as moderately susceptible. The varieties/lines showed susceptible response were BRJ-9072 (41.67\%), BRJ-1003 (33.34\%),
BRJ-1102 (26.67\%), BRJ-1103 (33.34\%), BRJ-1104 (43.34\%), BRJ-1201 (46.67\%), BRJ-1301 (30\%), BRJ1302 (40\%), BRJ-1304 (46.67\%), BRJ-1305 (31.67\%), BRJ-1306 (41.67\%), BRJ-1307(30\%), BRJ-1451 (30\%), BRJ-1453 (45\%), BRJ-1454 (30\%). Four lines were found highly susceptible $(50 \%$ and above disease incidence). BRJ-1452 showed the highest disease incidence of $60 \%$. Not even a single variety/line was found highly resistant, resistant or moderately resistant (Table 2). The results are summarized as $57 \%$ material was highly susceptible, $14 \%$ was moderately susceptible and $29 \%$ was highly susceptible (Figure 4 ). 
Table 2. Response of varieties/lines against disease

\begin{tabular}{|c|c|c|c|}
\hline Sr. & Varieties/Lines & \% Disease severity & Response \\
\hline 1 & BRJ-1004 & 23.34 & MS \\
\hline 2 & BRJ-1005 & 15 & MS \\
\hline 3 & BRJ-1455 & 21.67 & MS \\
\hline 4 & BRJ-1456 & 15 & MS \\
\hline 5 & BRJ-1457 & 21.67 & MS \\
\hline 6 & BRJ-1458 & 20 & MS \\
\hline 7 & BWP-RAYA & 18.34 & MS \\
\hline 8 & KNP-RAYA & 13.34 & MS \\
\hline 9 & BRJ-9072 & 41.67 & $S$ \\
\hline 10 & BRJ-1102 & 26.67 & S \\
\hline 11 & BRJ-1103 & 33.34 & $\mathrm{~S}$ \\
\hline 12 & BRJ-1104 & 43.34 & $\mathrm{~S}$ \\
\hline 13 & BRJ-1201 & 46.67 & $\mathrm{~S}$ \\
\hline 14 & BRJ-1301 & 30 & $\mathrm{~S}$ \\
\hline 15 & BRJ-1302 & 40 & $\mathrm{~S}$ \\
\hline 16 & BRJ-1304 & 46.67 & $\mathrm{~S}$ \\
\hline 17 & BRJ-1305 & 31.67 & $\mathrm{~S}$ \\
\hline 18 & BRJ-1306 & 41.67 & $\mathrm{~S}$ \\
\hline 19 & BRJ-1307 & 30 & $\mathrm{~S}$ \\
\hline 20 & BRJ-1451 & 30 & $\mathrm{~S}$ \\
\hline 21 & BRJ-1453 & 45 & $\mathrm{~S}$ \\
\hline 22 & BRJ-1454 & 30 & $\mathrm{~S}$ \\
\hline 23 & BRJ-9070 & 51.67 & HS \\
\hline 24 & BRJ-1003 & 33.34 & HS \\
\hline 25 & BRJ-1101 & 51.67 & HS \\
\hline 26 & BRJ-1205 & 31.67 & HS \\
\hline 27 & BRJ-1452 & 60 & HS \\
\hline 28 & BRJ-1105 & 51.67 & HS \\
\hline
\end{tabular}

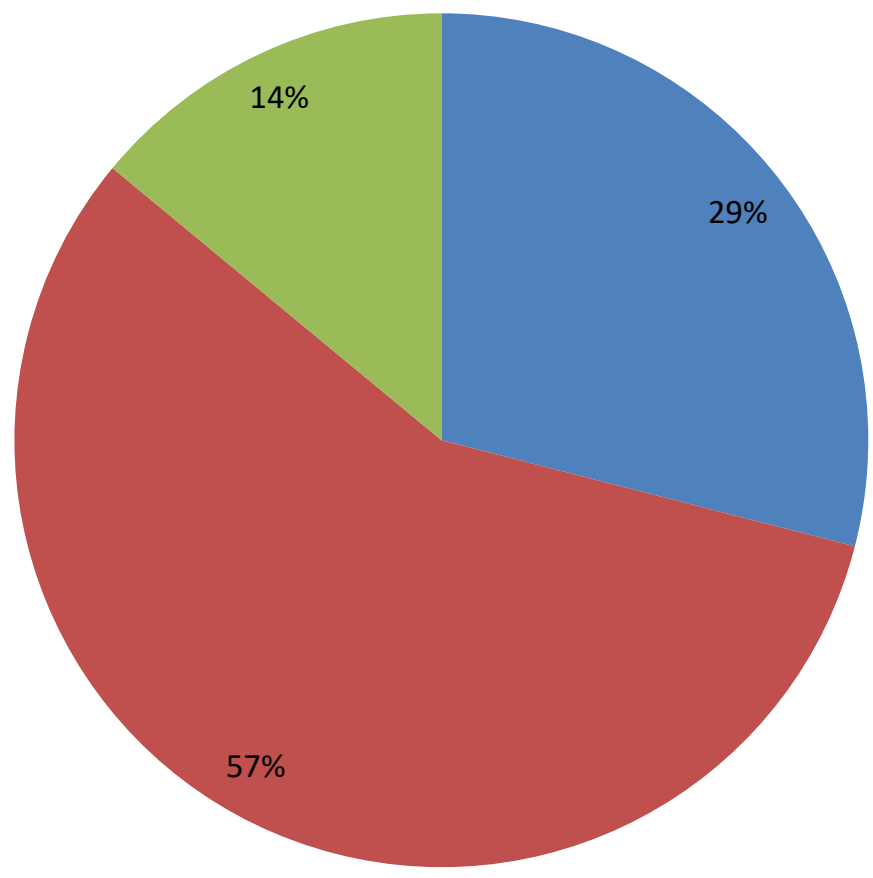

Moderately Susceptible

Susceptible

Highly Susceptible

Figure 4. Response of Varieties/lines against Alternaria blight 
Different researches have been conducted screening trials against Alternaria blight and our findings are similar to those with some variation which may be due to difference in environmental conditions and among races or genotypes of the pathogen(s). In past, several approaches aimed at to find out resistance source have been made but resistance source has not been reported in any specie of Brassica. Our research findings are similar to Rahman et al., 2010 who evaluated 26 rapeseed/mustard varieties/lines and found only 6 as moderately susceptible against the disease. The disease is externally and internally seed born. Gupta et al., 2017 conducted screening of thirty genotypes of rapeseedmustard and document their response against blight of mustard. He concluded that only four genotypes showed moderately resistance response while all others were susceptible towards disease. Singh et al., 2009 screened 81 lines of Indian mustard and reported that all the genotypes were susceptible and showed disease symptoms. In conclusion: Alternaria blight has adverse effects on yield, infected seeds and air borne spores act as source of inoculum. The pathogen overwinters on plant debris, host weeds and seed coats either internally or externally. The disease severity is greatly influenced by plant age, density of air borne conidia, wetness period, temperature and humidity. Weather conditions such as high relative humidity ( $>70 \%$ ), frequent rains and suitable temperature $\left(12-25^{\circ} \mathrm{C}\right)$ favor disease incidence and severity. A wet period (Leaf wetness) of minimum 4 hours is required for the occurrence of the infection. It was concluded that plant breeders and agricultural scientists design and implement such breeding programs which are particularly aimed at development of resistant germplasm against chronic disease Alternaria blight of mustard.

\section{REFERENCES}

Agrios, G. N. 2005. Introduction to plant pathology. Elsevier Academic Press Publication.

Akhtar, N., A. Shoaib and A. A. Nafisa. 2014. Identification and in vitro control of canola spot disease pathogen. Pakistan Journal of Phytopathology, 26: 103-108.

Berkeley, M. J. 1836. Fungi, in: Smith, J.E. and J.W. Hooker (Ed.), The English flora, Longman, London, pp. 339340.

Cho, Y., K.-H. Kim, M. La Rota, D. Scott, G. Santopietro, M. Callihan, T. K. Mitchell and C. B. Lawrence. 2009. Identification of novel virulence factors associated with signal transduction pathways in Alternaria brassicicola. Molecular Microbiology, 72: 13161333.

Choi, Y.-W., K. D. Hyde and W. Ho. 1999. Single spore isolation of fungi. Fungal diversity.

FAS. 2018. Oilseed: worlds markets and trade. Worlds production, markets and trade, December 11, 2018. United States Department of Agriculture.

Gupta, S., V. B. Singh, A. K. Singh, S. K. Rai, S. K. Singh and M. C. Dwivedi. 2017. Prevalence, Incidence and Management of Alternaria Blight of Rape-Seed and Mustard (Brassica juncea L) through Resistance and Integrated Approach. International Journal of Current Microbiology and Applied Sciences, 6: 2730-2741.

Humpherson-Jones, F. M. 1989. Survival of Alternaria brassicae and Alternaria brassicicola on crop debris of oilseed rape and cabbage. Annals of Applied Biology, 115: 45-50.

Khan, M., N. Singh and N. Khan. 1998. Incidence of Alternaria blight of mustard, cabbage and cauliflower in the Aligarh district. Chem. Environ. Res, 7: 111-116.

Kolte, S. and R. Awasthi. 1987. Assessment of yield losses due to Alternaria blight in rapeseed and mustard. Indian phytopathology, 40: 209-211.

Kolte, S. J. 1985. Disease of Annual Edible oilseed crops. Mustard and Sesame Disease. CRC Press Inc. Boca Raton. Florida, p. 135.

Mamgain, A., R. Roychowdhury and J. Tah. 2013. Alternaria pathogenicity and its strategic controls. Research Journal of Biology, 1: 1-9.

McDonald, W. C. 1959. Gray leaf spot of rape in manitoba. Canadian Journal of Plant Science, 39: 409-416.

Meah, M. B. 1994. Diseases of sunflower in Bangladesh. Report submitted to CDP, DAE, Khamarbari, Dhaka1215, p. 14.

Mridula, K., A.K. Mohanty, N. N. Acharya and P. N. Sethi. 1994. Efficacy of some selective fungicides against Alternaria brassicae causing leaf blight of Mustard. Orissa Journal of Agricultural Research 7: 90-91.

Prasad, R. 2006. Management of Alternaria blight of mustard with combination of chemicals and botanicals. Annals of Plant Protection Sciences, 14: 400-403.

Rahman, M., F. Elahi and B. Goswami. 2010. Screening of Rapeseed-mustard varieties/lines against Alternaria blight disease. Annual Report Bangladesh Agricultural Research Institute, 
Gazipur: 1-2.

Saharan, G. and N. Mehta. 2002. Fungal diseases of rapeseed-mustard. Diseases of field crops: 193-228.

Shrestha, S. K., L. Munk and S. B. Mathur. 2010. Role of weather on Alternaria leaf blight disease and its effect on Yield and Yield Components of Mustard. Nepal Agriculture Research Journal, 6.

Singh, V., K. Kumar, R. Bhajan, P. Singh and R. Singh. 2009. Identification of resistances sources against
Alternaria blight and white rust in Indian mustard. Journal Oilseed Research, 26: 435-436.

Verma, P. R. and G. S. Saharan. 1994. Monograph on Alternaria diseases of crucifers. Minister of Supply and Services. Saskatoon, Canada.

Yadav, R., A. Kumar, A. Kumar and S. Verma. 2014. Screening of rapeseed-mustard cultivars/lines for resistance against Alternaria blight. Indian Journal of Scientific Research, 5: 89. 